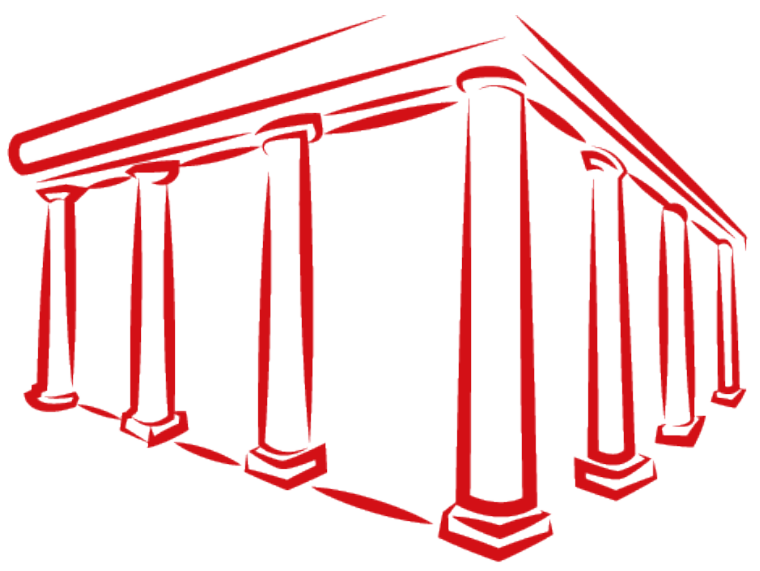

Clínica Jurídica

per la Justícia Social

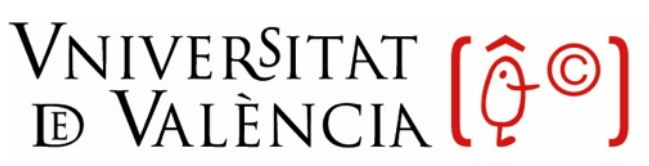

Facultat de Dret

\title{
La discriminación en el acceso a la federación deportiva de las personas que viven o conviven con VIH en el ámbito de la Comunitat Valenciana
}

Ana de Sousa Selfa

Victorino Domingos

Christian Proaño Guzmán

Andrea Granda Iñiguez

Tutor:

Andrés Gascón Cuenca

Clínica Jurídica per la Justícia Social | Facultat de Dret | Universitat de València 


\section{Índice}

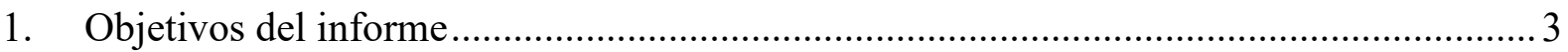

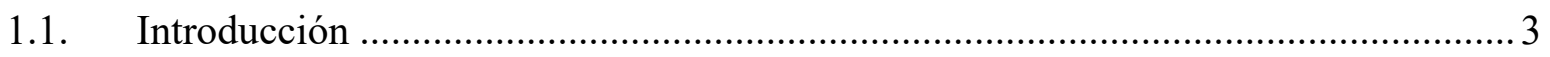

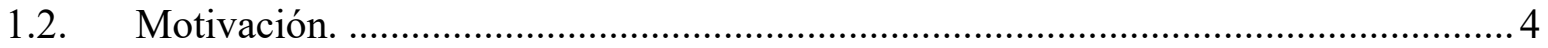

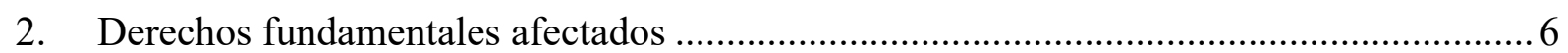

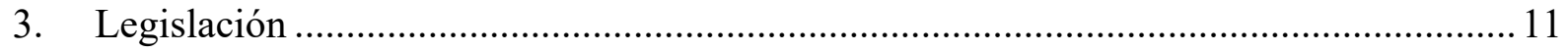

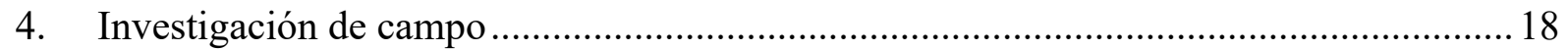

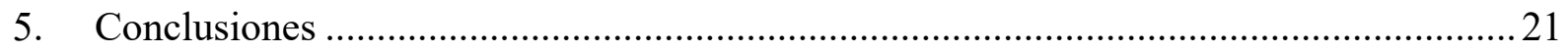

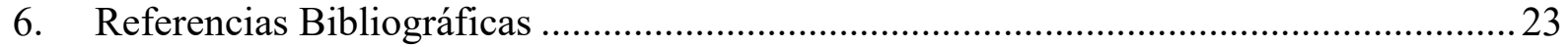

Este trabajo se encuentra bajo una licencia Creative Commons Attribution-NonCommercialShareAlike 4.0 International

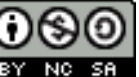

Las ideas, afirmaciones o expresiones contenidas en el presente informe son responsabilidad exclusiva del grupo de autores, no teniendo porque ser compartidas por CESIDA, la Universitat de València, la Facultat de Dret de la Universitat de Valencia, o la Clínica Jurídica per la Justícia Social de la UV.

Puede contactar con el grupo de autores a través del correo electrónico: clinica@uv.es 


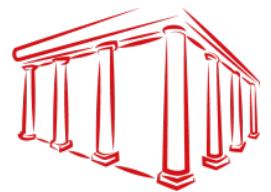

\section{Objetivos del informe}

\subsection{Introducción}

El presente informe ha sido realizado por un grupo de estudiantes del Máster en Derechos Humanos, Democracia y Justicia Internacional pertenecientes a la Clínica Jurídica per la Justícia Social de la Facultat de Dret de la Universitat de València. El mismo tiene por objeto la realización de una investigación de carácter jurídico-social respecto a la posible situación de discriminación que pueden estar afectando a las personas que viven o conviven con VIH dentro del ámbito deportivo. Concretamente, este estudio se centra en los requisitos establecidos por las federaciones deportivas ubicadas en el ámbito territorial de la Comunitat Valenciana para acceder al deporte profesional o federado.

La realización de esta investigación se estructurará de la siguiente manera. En primer lugar, se realizará una breve referencia a la razón que motiva el informe, es decir, a la necesidad detectada que nos indujo a efectuar esta investigación. En segundo lugar, se valorará desde el punto de vista constitucional el razonamiento argumentado para la realización de pruebas serológicas de VIH respecto al acceso a la federación deportiva, revisando desde el criterio de la proporcionalidad si sería constitucionalmente aceptable que las personas que conviven con VIH tengan la obligación de presentar un examen serológico de VIH para acceder al carácter de federado, o si al contrario, esto supone una vulneración de derechos fundamentales. En tercer lugar, nos referiremos de forma breve a la normativa internacional y nacional concerniente a la cuestión investigada, en cuanto a la regulación del proceso de federación deportiva y al tratamiento de datos de carácter personal, de igual manera, a lo pertinente en cuanto a la legislación relativa en materia de igualdad, dignidad y no discriminación. Posteriormente, se expondrán de forma clara y sintética los datos y resultados obtenidos del estudio de campo realizado en el período de elaboración del presente informe ${ }^{1}$, el cual ha consistido en contactar a la totalidad de federaciones deportivas de la Comunitat Valenciana, con el objetivo de solicitar información concerniente a los requisitos exigidos a las personas que deseen federarse. De esta manera, nos ha sido posible conseguir una visión clara del estado de la cuestión dentro de este ámbito territorial y obtener un conocimiento tanto a nivel cuantitativo como cualitativo de las federaciones que solicitan exámenes serológicos de VIH para que una persona pueda proceder a la federación. Por último, se presentará un apartado en el que se sinteticen las conclusiones alcanzadas.

\footnotetext{
${ }^{1}$ Desde diciembre de 2018 hasta marzo de 2019
} 


\subsection{Motivación.}

El presente informe ha sido elaborado con el objetivo de ofrecer una argumentación jurídica clara y completa para combatir, en la práctica, algunas de las situaciones de discriminación que las personas que conviven con VIH experimentan a lo largo de su vida, analizando ciertas restricciones a las que se ven expuestas respecto de la limitación de la igualdad de trato, oportunidades y participación dentro del ámbito deportivo.

En este sentido, es necesario mencionar que la Coordinadora Estatal de VIH y Sida (CESIDA) recibió una consulta por parte de una persona a la que le exigieron exámenes médicos en los que se le obligaba a exponer su situación serológica de VIH para poder acceder a una federación deportiva.

Es importante destacar que en la actualidad no existen antecedentes documentados en lo que respecta a transmisión de VIH por actividades deportivas. Además, las distintas federaciones dentro de la Comunitat Valenciana han creado sus propios estatutos, técnicas de educación y prevención en el ámbito de la protección de la salud de los deportistas, no solo con respecto al VIH, sino en general respecto al cuidado de la salud de la comunidad deportiva. Siendo así es menester recalcar que, prima facie, no parece estar justificada la obligatoriedad de la prueba serológica de VIH para decidir sobre la aceptación de un deportista en cualquiera de las diferentes formas de participación previstas en las diferentes federaciones deportivas.

El deporte en la actualidad es una actividad de extraordinaria importancia social, que fomenta e incentiva valores sociales de participación, respeto, cooperación, relación social, trabajo en equipo, convivencia y lucha por la igualdad. De este modo, cuando hablamos de igualdad nos referimos a que las distintas actividades deportivas deben mantener un carácter abierto, que impida que se generen situaciones que podrían suponer algún tipo de discriminación para las personas que quieran practicar estas actividades.

De este modo, la Constitución española, en sus artículos 9 y 14, garantiza la libertad e igualdad formal y material de las personas, fomenta el libre desarrollo de la personalidad y la remoción de obstáculos que puedan dificultar la participación de los ciudadanos en cualquier forma de participación y de igual manera establece que se fomentará la educación física y el deporte. Siendo así, el deporte dentro de la sociedad cumple un rol fundamental que acarrea 


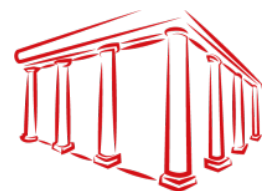

beneficios físicos, psicológicos y sociales, puesto que es un instrumento encaminado al desarrollo integral del ser humano, que crea un elemento integrador y que desarrolla la seguridad, autoestima y confianza de las personas que participan. Por lo tanto, fomenta y defiende la igualdad, justicia, solidaridad e integración, puesto que uno de los objetivos del deporte, en tanto que disciplina de desarrollo integral y personal, es combatir los prejuicios, estereotipos y discriminaciones que se puedan generar dentro de este ámbito.

Además de lo anterior, es necesario destacar que la presencia de estigmas y prejuicios es el motor que ha generado que exista discriminación hacia las personas que conviven con VIH. El estigma asociado al VIH genera desigualdades sociales y de comportamientos relevantes que afectan a todas las áreas de la vida, incluso en el ámbito deportivo, lo que genera un trato parcial e injusto y produce una vulneración de derechos fundamentales creando grandes barreras sociales.

Es desde esta realidad fáctica de injusticia que la Clínica Jurídica per la Justícia Social de la Facultat de Dret de la Universitat de València, partiendo del compromiso social que le da sentido, realiza este informe en colaboración con CESIDA, donde se clarifica la cuestión planteada, partiendo del análisis del estado de la situación y creando una argumentación jurídica que permita informar a las federaciones sobre las irregularidades y vulneraciones de derechos fundamentales que pueden estar cometiendo, con la finalidad de que estas situaciones puedan ser corregidas. 


\section{Derechos fundamentales afectados}

En este segundo apartado, se valorarán cuáles son los derechos fundamentales de las personas que conviven con VIH que se ven afectados por la situación referida en el apartado anterior, esto es, cuando se les exige la realización de un examen serológico con el fin de acceder a la federación para la práctica de un deporte.

A este respecto, Pérez (1998) expone la importancia de recordar que los derechos fundamentales son aquellos derechos básicos, universales, inalienables, indivisibles, irrenunciables e interdependientes que deben ser respetados en cualquier circunstancia y por parte de cualquier organismo o persona. Partiendo de esta idea debe reconocerse que durante la articulación de los mismos, en la práctica, se producen habitualmente colisiones entre estos. Dichas colisiones implican que sea necesario realizar una valoración de qué derecho debe ceder, así como de qué forma debe hacerlo en cada caso determinado. El objetivo de dicha ponderación es el de poder mantener la coherencia con respecto al sentido último que la estructura jurídica de los derechos humanos, en cuanto garantías mínimas de vida digna para todas las personas. En este sentido es evidente que como consecuencia de estas colisiones, las expectativas que se tienen sobre el carácter de una práctica absoluta de los derechos humanos deben verse puestas en relación con esta realidad fáctica en que la articulación conjunta de estos provoca limitaciones y restricciones en la práctica de los mismos. Así pues, a la vez que se afirma el carácter absoluto de cada uno de los derechos humanos, se matiza que su puesta en práctica debe quedar orientada hacia la consecución del sentido general completo del conjunto de toda la estructura de los derechos humanos como concepto. Es por esto que cualquier restricción que se produzca en la práctica en relación a cualquiera de los derechos humanos, deberá ser proporcionada y limitarse a lo estrictamente necesario.

La forma que se tiene de aplicar estas ideas sobre los derechos humanos al terreno de la protección de los derechos fundamentales en el ámbito estatal, se relaciona con valorar el conjunto de principios que ordenan el sistema jurídico del Estado, en concreto y en el caso español, haciendo referencia a la Constitución como en cuanto cúspide del ordenamiento.

Siguiendo esta línea, es evidente que al hablar de la obligatoriedad de realizarse unas pruebas médicas y el hecho de que los resultados de estas vayan a ser uno de los factores a valorar para aceptar o no la federación deportiva de una persona, hay varios derechos fundamentales que se ven restringidos en su puesta en práctica. El derecho a la intimidad (art. 


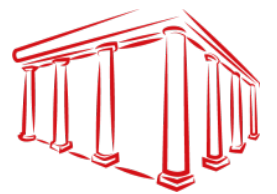

18.1CE), la no discriminación y el derecho a un trato igualitario (art. 9.2 CE y art. 14 CE) son los derechos que se ven directamente afectados por esta situación. De lo que se trata, por tanto, es de dilucidar si dicha afectación producida en este tipo de situaciones analizadas, supera el test o criterio de constitucionalidad, y comprobar así la proporcionalidad y necesidad de tales restricciones.

En este sentido, es importante comentar que el test de constitucionalidad, y la forma en que este se aplica como método de valoración nos permite comprobar si la situación que nos encontramos analizando de conflicto de derechos fundamentales se está produciendo de forma acorde o no a los principios superiores que orientan nuestro ordenamiento jurídico ${ }^{2}$.

Así, de acuerdo con Borowski (2016) el test de constitucionalidad funciona como un marco de medición que engloba los parámetros que delimitan las circunstancias en las que es legítimo que la ordenación de la vida social (el Derecho como institución) afecte a los derechos fundamentales de las personas, teniendo en cuenta que esta afectación interfiere en la esfera inalienable y última de estas. El test de constitucionalidad se articula en torno a diversos parámetros que a continuación serán estudiados y valorados en profundidad. Estos parámetros son: temporalidad, abstracción, adecuación al principio de legalidad, justificación teleológica última, principio de proporcionalidad, idoneidad y necesidad de la medida.

Así pues, con respecto al primero de estos parámetros, este se refiere a la necesaria temporalidad que la afectación al derecho debe tener. En este sentido, no se acepta que una persona quede excluida de forma permanente del disfrute de alguno de sus derechos fundamentales, sino que la restricción deberá tener una temporalidad claramente definida. De acuerdo con este primer parámetro, resulta difícil justificar la obligatoriedad de someterse a un examen serológico. En primer lugar, el estado serológico no cambiará nunca (al menos en términos del nivel actual de avance médico sobre la cuestión), $\mathrm{y}$, por tanto, nunca se conseguirá un resultado en el examen que permita la federación de la persona que convive con VIH. En segundo lugar, una vez que los resultados del examen llegan al conocimiento de las personas encargadas de valorarlos, estas ya no dejarán nunca de contar con esa información sobre la persona concreta. En términos de derechos afectados, la exclusión que la persona sufre de la posibilidad de federarse debido a su estado serológico no variará con el tiempo, es decir, la persona no podrá federarse nunca (mientras no exista una cura), y será

\footnotetext{
${ }^{2}$ España se constituye en un Estado social y democrático de Derecho, que propugna como valores superiores de su
} ordenamiento jurídico la libertad, la justicia, la igualdad y el pluralismo político (Art. 1.1 CE) 
discriminada de forma permanente. En cuanto a la vulneración temporal del derecho a la intimidad, esta será irreversible y definitiva, pues la información sobre sus datos médicos ya habrá sido transmitida, abandonando la esfera eminentemente privada, situación que no podrá retrotraerse a estado previo.

Continuando con los factores englobados dentro del test de constitucionalidad, nos encontramos con la exigencia de que existan unos presupuestos de aplicación general para el conjunto de la ciudadanía, es decir, unos criterios que puedan considerarse y aplicarse de forma abstracta. Esta referencia tiene un vínculo claro con el principio de legalidad, y es precisamente este principio el que concretiza el factor a valorar en el referido test. A este respecto, cabe decir que el test de constitucionalidad exigiría la existencia de normativa ( $\sin$ especificar el rango normativo) específica que hiciera referencia a la cuestión, de manera que quedase legalmente sustentado que es necesario exigir una prueba serológica para poder aceptar o rechazar el acceso a la federación deportiva de una persona. Este punto se analizará en detalle más adelante, cuando se hable de la legislación, pero ante todo cabe destacar que en España no existe ningún precepto legal que, en el ámbito del deporte, obligue o faculte a las federaciones deportivas a exigir un examen médico de estas características a las personas que quieren acceder a ellas. Así, la realidad que se está produciendo en las situaciones denunciadas no encuentra sustento alguno en la legislación actual vigente en nuestro ordenamiento jurídico y por lo tanto cabe calificarla como discriminatoria. De hecho, y aunque esto también será mencionado con más detalle en el apartado 3 del presente informe, es pertinente destacar que incluso en otros escenarios en los que hace bien poco existían barreras que suponían discriminación para las personas que conviven con VIH (como por ejemplo en lo que respectaba al acceso a la función pública), estas se han eliminado.

Siguiendo con la aplicación del test de constitucionalidad, otro de los factores que este contiene como parámetro a valorar para conocer la posible valoración injustificada de un derecho fundamental, es el llamado principio de justificación teleológica. Este principio se refiere a la necesaria exigencia de que exista un fin último, de entidad, que justifique el porqué de la restricción. En este caso concreto, se entiende que el fin de la medida aquí analizada es la protección de la salud pública en general y de la integridad y salud personal del resto de personas federadas con las que se pudiese llegar a compartir la práctica del deporte. Como se puede ver, este parámetro del test, a diferencia de lo que pasaba con los anteriormente analizados, si parece cumplirse a primera vista, pues no queda duda de la Clínica Jurídica per la Justícia Social | Facultat de Dret | Universitat de València 


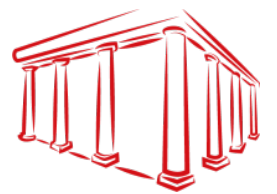

importancia fundamental y constitucionalmente justificada del fin perseguido. Sin embargo, a este respecto y antes de poder afirmar que el fin perseguido es adecuado, cabe analizar pormenorizadamente la realidad concreta del caso, es decir, cabe preguntarse cuál es el riesgo verdadero al que la salud pública y la integridad personal quedan sometidas en el caso de que se produjese una práctica deportiva compartida con una persona que convive con VIH. Para poder analizar este riesgo, es necesario tener en cuenta que para hablar de VIH y seropositividad es indispensable, en primer lugar, realizar una tarea de formación básica acerca de lo que implica. Es necesario entender cuál es el estado de la cuestión a nivel de tratamientos, así como conocer las vías, las formas y los antecedentes de transmisión que existen, pues solo partiendo de una buena base informativa previa se podrá responder sobre la adecuación, necesidad y proporcionalidad de las medidas adoptadas para la consecución del fin deseado. En este sentido, y por lo que respecta a la información médica de la cuestión, hay que destacar que, por un lado, no existe a día de hoy ningún caso documentado de transmisión de VIH en el ámbito deportivo. Además, las vías de transmisión están debidamente identificadas, y es en relación a estas, se han establecido las conocidas como Medidas Universales de Prevención de la Transmisión (MUPT), a las que hay que atender a la hora de establecer protocolos de actuación durante la práctica deportiva. En este sentido, es conveniente aclarar el sentido en que funcionan y se aplican estas MUPT y la importancia que estas tienen desde el punto de vista de la lucha contra la discriminación y el respeto de los derechos humanos. El objetivo principal de las MUPT es el de reducir al mínimo los riesgos de transmisión, para ello, lejos de buscar un control absoluto, constante e imposible sobre el estado serológico de las personas, las MUPT establecen una serie de reglas para el tratamiento de todos aquellos fluidos que se consideran potencialmente infecciosos en relación a cualquier tipo de patógeno transmitido por sangre. Ramiro y Rodríguez señalan la importancia que estas medidas tienen, desde el punto de vista de los derechos humanos, al basar la prevención en pautas de actuación generales y no en actuaciones que se deban tomar de forma específica hacia las personas que conviven con el virus. En este sentido:

\footnotetext{
"Las MUPT son sumamente importantes ya que evitan que se adopten medidas especiales con determinadas personas (...)permiten desarrollar el principio de igualdad ya que implica que todas las personas son iguales en la percepción del riesgo y que todas deben ser tratadas de forma similar pues los derechos y las cargas deben distribuirse de forma equitativa" (Ramírez A. y Rodríguez P., 2015, p. 15).
} 
Por otro lado, además, los informes y estudios médicos confirman que las personas sometidas a terapia antirretroviral (TAR), consiguen y mantienen una carga viral indetectable ${ }^{3}$, y en estas circunstancias, no pueden transmitir el virus ${ }^{4}$. Estos dos hechos nos indican que no quedaría justificado que la exclusión de federación deportiva de las personas conviven con VIH sea una medida adecuada ni idónea para el fin perseguido, pues remitiéndonos a la falta de antecedentes de contagio en el ámbito deportivo, y teniendo en cuenta el estado médico de la cuestión, ni la salud pública ni la integridad personal del resto de deportistas sufren un riesgo real si se siguen las precauciones y Medidas Universales de Prevención de la Transmisión del VIH.

Por tanto, la conclusión a las que podemos llegar tras este análisis y valoración de los derechos afectados en la situación estudiada, es que no es constitucionalmente aceptable que se obligue a las personas a realizarse un examen serológico para poder federarse en cualquier federación deportiva, pues la medida no tiene sustento legal alguno, no tiene un carácter transitorio y en la ponderación de derechos se observa que la vulneración que sufrirían las personas a los que se obliga a realizarse la prueba es ampliamente desproporcionada en relación al riesgo mínimo que su no discriminación supondría para el resto de la población.

\footnotetext{
${ }^{3}$ Por debajo de 200 copias $/ \mathrm{ml}$.

${ }^{4}$ Comunicado de la Organización Mundial de la Salud (18 de Julio de 2018).

Clínica Jurídica per la Justícia Social | Facultat de Dret | Universitat de València

clinica@uv.es | uv.es/clinica
} 


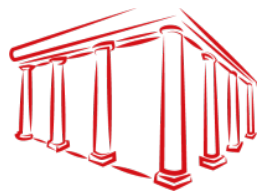

\section{Legislación}

En este tercer apartado realizaremos una investigación sobre la legislación existente, con el fin de determinar si la exigencia de un examen serológico de VIH se convierte en un factor discriminatorio para las personas que conviven con VIH que desean practicar deporte, tanto a nivel amateur como de alto rendimiento. Para esto, empezaremos analizando el ámbito internacional donde se definen los derechos fundamentales de las personas, hasta llegar al ámbito comunitario, y posteriormente nacional, que garantizan la igualdad y libre participación deportiva a las personas.

Si partimos desde el punto de vista de los actos discriminatorios, la Declaración Universal de los Derechos Humanos (DUDH) de 1948 nace con el objetivo de combatir la desigualdad y cualquier forma de discriminación, consagrando derechos como la igualdad y a ser protegido por la ley ante cual acto discriminatorio, como nos lo explica su artículo 7: las personas son iguales ante la ley y tienen, sin distinción, derecho a igual protección de la ley. Todos tienen derecho a igual protección contra toda discriminación que infrinja esta Declaración y contra toda provocación a tal discriminación.

Derechos como este, de igualdad, protección y de no discriminación consagrados en la DUDH, han servido de base para que posteriormente los Estados elaboren y suscriban pactos, tratados o convenios internacionales que de manera vinculante, garanticen su cumplimiento, pero a más de eso se extienden estos derechos ante cualquier injerencia que atente contra la dignidad y la vida privada de las personas, como lo veremos a continuación.

El Pacto Internacional de Derechos Civiles y Políticos, vigente desde 1976, contempla en su artículo 17 que nadie será objeto de injerencias arbitrarias o ilegales en su vida privada, su familia, su domicilio o su correspondencia, ni de ataques ilegales a su honra y reputación. A demás, toda persona tiene derecho a la protección de la ley contra esas injerencias o esos ataques.

De la misma forma, el artículo 8.1 del Convenio Europeo de Derechos Humanos vigente desde 1953, establece que toda persona tiene derecho al respeto de su vida privada y familiar, de su domicilio y de su correspondencia.

Estos dos instrumentos internacionales contemplan el respeto del derecho de la vida privada de las personas, ya que su vulneración podría dar lugar a una serie ataques 
injustificados que le corresponde al Estado proteger, como lo dicen las observaciones generales aprobadas por el Comité de Derechos Humanos de Naciones Unidas:

\begin{abstract}
"Las obligaciones impuestas por este artículo exigen que el Estado adopte medidas legislativas y de otra índole para hacer efectivas la prohibición de esas injerencias y ataques y la protección de este derecho"s.
\end{abstract}

Esta vulneración del derecho a la vida privada de una persona, puede darse con el objetivo de conocer información personal que más adelante será considerada para la toma de una decisión que puede dar como resultado una exclusión injustificada, como vuelve a establecer el Comité de Derechos Humanos de Naciones Unidas:

\footnotetext{
"Un ejemplo de violación a este derecho lo constituye la solicitud de prueba de embarazo de los empleadores a las mujeres que optan por un empleo, pues en ese momento se interfiere en la vida privada de las mujeres" ${ }^{\circ}$.
}

Como vemos, la solicitud de información personal de forma injustificada es un factor determinante para violar el derecho a la vida privada de una persona, como es el caso del requerimiento del examen serológico de VIH previo a federarse, en donde no existe una justificación, atentando contra la voluntad de la persona, tal y como explica el Informe de ONUSIDA del año 2004: "el proceso de las pruebas, con independencia del contexto, tiene que seguir siendo voluntario, y hay que preservar la naturaleza confidencial del resultado" (ONU, 2014, p. 86).

Este tipo de exámenes, mientras no sean voluntarios y confidenciales, constituyen la antesala para una serie de violaciones a los derechos humanos, como el de igualdad y el de no discriminación, afectando directamente al reconocimiento de derechos de las personas que conviven con VIH y a su plena integración en la sociedad.

Esto ha dado como resultado la firma de varios documentos internacionales como la Declaración Final de la Cumbre de París sobre el SIDA, de 1994, firmada por 42 Estados y la Declaración y Plan de Acción de Nueva Delhi sobre el VIH y el SIDA de Derecho y Humanidad de 10 de diciembre de 1995, en donde se busca que los Estados parte promuevan y protejan a las personas que conviven con VIH y el SIDA.

${ }^{5}$ COMITÉ DE DERECHOS HUMANOS. Observación General Número 16. 32º período de sesiones (1988). Derecho a la intimidad (artículo 17).

${ }^{6}$ COMITÉ DE DERECHOS HUMANOS. Observación General Número 28. $68^{\circ}$ período de sesiones (2000). La igualdad de derechos entre hombres y mujeres (artículo 3)1, párrafo 20. 


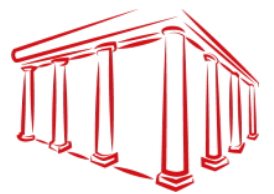

Además, la Comisión de Derechos Humanos de las Naciones Unidas mediante Resolución 1996/43, de 19 de abril, expide la protección de los derechos humanos de las personas que conviven con VIH o SIDA, en donde remite directrices a los Estados miembros con el objetivo de combatir la discriminación:

"La discriminación sobre la base de un posible contagio por VIH o SIDA, real, está prohibida por las normas internacionales vigentes en materia de derechos humanos y que la expresión "o cualquier otra condición social", que figura en las disposiciones sobre no discriminación que figuran en textos internacionales de derechos humanos debe interpretarse en el sentido de que abarca el estado de salud, incluso el VIH y el SIDA".

De igual forma exhorta a todos los Estados a que se cercioren, cuando sea necesario, de que sus leyes, políticas y prácticas, incluidas las introducidas en relación con el VIH o el SIDA, respetan las normas de derechos humanos, prohíben la discriminación relacionada con el VIH o el SIDA y la introducción de leyes protectoras y de una educación apropiada para combatir la discriminación, los prejuicios y el estigma, a fin de garantizar el pleno disfrute de los derechos civiles, políticos, económicos, sociales y culturales de las personas que viven o conviven con el VIH o el SIDA.

Combatir la discriminación y la brecha existe entre la sociedad y las personas que conviven con VIH, debido a los estigmas que han ido surgiendo a lo largo de las 3 décadas desde su aparición, no ha sido tarea fácil para la ONU ni para los Estados, es por eso que en el año 2000 se plantean 8 Objetivos de Desarrollo del Milenio para todos los países integrantes de la ONU, entre los que encontramos la participación social a las personas que conviven con VIH:

“ODM 6: combatir el VIH y el SIDA, el paludismo y otras enfermedades. De forma similar al ODM 5, los Ministerios de Sanidad y de Educación están colaborando con ONG y con otros gobiernos locales para desarrollar y coordinar actividades deportivas encaminadas al fomento de la salud y a la participación de las personas con enfermedades. Así mismo, se están respaldando programas de actividades con el fin de erradicar las enfermedades a través de publicaciones que tratan de informar a las personas sobre las enfermedades y su prevención”. 
Desde entonces, después de 15 años para conocer su cumplimiento, estos objetivos tuvieron su primera evaluación en el año 2015, arrojando resultados positivos para España, lo que servirá como base para los nuevos objetivos que serán evaluados en el año 2030.

Pero a pesar de que España consiguió cumplir con los ODM en el año 2015, todavía nos encontramos en la actualidad con organismos e instituciones deportivas que injustificadamente solicitan exámenes serológicos de VIH previos a obtener la licencia deportiva, contraviniendo no solo a la norma internacional de protección y no discriminación del que es parte el Estado español, si no también afectando directamente en la vida personal y deportiva de las personas que conviven con VIH.

Enfocándonos ahora dentro del área local, vamos a observar que la legislación nacional se encuentra alineada a los compromisos y obligaciones de los tratados y convenciones internacionales de derechos humanos antes vistas.

Antes de entrar a analizar detenidamente la regulación en materia deportiva, obligatoriamente tenemos mencionar varios principios de la Constitución española de 1978, que en su artículo 9.2CE establece que les corresponde a los poderes públicos promover las condiciones para que la libertad y la igualdad del individuo y de los grupos en que se integra sean reales y efectivas; remover los obstáculos que impidan o dificulten su plenitud y facilitar la participación de todos los ciudadanos en la vida política, económica, cultural y social.

En el primer apartado del artículo, observamos el mandato de la Constitución hacia los poderes públicos para que sean estos quienes promuevan los derechos de libertad e igualdad de las personas, pero no se refiere a la misma igualdad que nos habla el artículo 14CE, sino una igualdad material o sustancial, como lo dice el Tribunal Constitucional en su sentencia 39/1986, de 31 de marzo:

\footnotetext{
"La Constitución española es un precepto que compromete la acción de los poderes públicos, a fin de que pueda alcanzarse la igualdad sustancial entre los individuos, con independencia de su situación social".
}

En otras palabras, podríamos decir que no únicamente se refiere a una igualdad de todas las personas ante la ley, sino que además se refiere a que los poderes del Estado a través de la potestad que les entrega la ley, deben garantizar una real y efectiva igualdad a las personas indistintamente de su condición. 


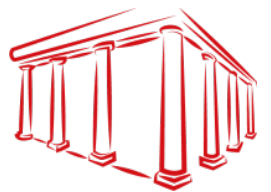

Según Prieto Sanchís (1995) la "igualdad material o sustancial, esto es, como derechos, no a defenderse ante cualquier discriminación normativa, sino a gozar de un régimen jurídico diferenciado o desigual en atención precisamente a una desigualdad de hecho que trata de ser limitada o superada" (p. 17).

La explicación de Prieto Sanchís sobre igualdad material o sustancial, nos deja claro que los poderes del Estado deben velar por crear un régimen jurídico que atienda las desigualdades sociales existentes para poder superarlas, complementándose con el segundo apartado del artículo 9.2CE, en el cual se establece que se debe remover los obstáculos que impidan o dificulten su plenitud y facilitar la participación de todos los ciudadanos en la vida política, económica, cultural y social, siendo parte de ellos el deporte.

Al hablar de garantizar una participación a toda la ciudadanía en el ámbito que fuere, incluso en el deportivo, no debemos olvidar que esta participación está acompañada de otros derechos humanos irrenunciables, como el de la dignidad, el de libre desarrollo de la personalidad humana y el respeto a ley y a los derechos de los demás, como lo establece el artículo 10.1CE, con el objetivo de que la legislación pueda prevenir actos discriminatorios o demás violaciones de los derechos de una persona deportista por cualquier condición.

En el caso deportivo, el legislador español ha expedido la Ley del Deporte 10/1990, de 15 de octubre, como normativa general en este ámbito, la que reconoce en su artículo 1.2 que la práctica del deporte es libre y voluntaria como factor fundamental de la formación y del desarrollo integral de la personalidad, constituyendo una manifestación cultural que será tutelada y fomentada por los poderes públicos del Estado.

Es así que los poderes públicos del Estado al tener que garantizar esa igualdad sustancial prevista en el artículo 9.2 de la Constitución, deberían proteger de la misma forma que protege al resto de personas, a los deportistas que conviven con VIH sobre cualquier acto que atente su vida privada que pueda dar lugar a discriminaciones, cosa que hasta el momento no se ha realizado.

El Estado español ha formado comisiones, unidades de control y reglamentos en torno a la Ley 19/2007, de 11 de julio, contra la violencia, el racismo, la xenofobia y la intolerancia en el deporte, pero para este caso en particular, se mantiene un vacío legislativo que por el momento deja indefensos a los deportistas que conviven con VIH. 
Las personas que conviven con VIH tienen la misma capacidad física que cualquier otra persona para la práctica de deportes de alto rendimiento, o a nivel amateur o profesional, llevando una vida normal dentro y fuera del escenario deportivo. Sin embargo, deben soportar el estigma del desconocimiento, sobre todo cuando es necesario informar sobre su condición ante reconocimientos o exámenes médicos ${ }^{7}$.

La solicitud de un reconocimiento o examen médico, debemos advertir que se encuentra contemplado en el artículo 46 de la Ley Orgánica 3/2013, de 20 de junio, expedida para la protección de la salud del deportista y lucha contra el dopaje en la actividad deportiva, estableciendo que:

El Consejo Superior de Deportes determinará, progresivamente, la obligación de efectuar reconocimientos médicos con carácter previo a la expedición de la correspondiente licencia federativa, en aquellos deportes en que se considere necesario para una mejor prevención de los riesgos para la salud de sus practicantes.

De la misma manera la Ley 2/2011, de 22 de marzo, del deporte y la actividad física de la Comunitat Valenciana, dispone en su artículo 16:

Medidas de protección a los deportistas federados. Las federaciones deportivas podrán establecer la obligatoriedad de un reconocimiento médico previo del deportista que determine la no existencia de contraindicaciones para la práctica de su modalidad deportiva.

Por lo que, las federaciones deportivas de la Comunitat Valenciana se encuentran en la capacidad legal de establecer la obligatoriedad de un reconocimiento médico previo a la obtención de la licencia deportiva, siempre y cuando sea su objetivo el prevenir y proteger la salud del deportista ante cualquier contraindicación al momento de realizar una actividad física. Sin embargo, esta situación tal y como se ha argumentado a lo largo del presente informe, dista de forma mayúscula de los reconocimientos médicos solicitados con el único fin de conocer o identificar a deportistas que conviven con VIH en contra de su voluntad y que no tienen por fin la protección de la salud del deportista que se los realiza.

\footnotetext{
${ }^{7}$ Eldiario.es. El VIH en el deporte sigue envuelto en un silencio como el de los años 80, publicado en el 2017 https://www.eldiario.es/sociedad/Deportistas-VIH-estigma-desconocimiento_0_716028574.html
} 


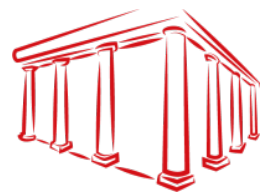

Como podemos ver en todo el recorrido de la legislación existente sobre el tema que nos ocupa, los derechos humanos consagrados en varios documentos protegen la igualdad de todas las personas sin exclusión, siendo un factor determinante el que nadie, persona natural o jurídica, pública o privada, de forma injustificada invada el derecho a la vida privada de una persona, forzándola a someterse a reconocimientos o exámenes contra su voluntad. Ante esto el Estado como garantista de la protección de la igualdad sustancial, se encuentra en la capacidad de legislar para regular los derechos de las personas que conviven con VIH en el ámbito deportivo y protegerlos frente a cualquier comportamiento discriminatorio. En este sentido, la Orden PCI/154/2019, de 19 de febrero, expedida por el Ministerio de la Presidencia, decidió eliminar el VIH de las causas de exclusiones médicas exigibles para el acceso al empleo público, así como limitar de las causas de exclusiones médicas exigibles en todas las convocatorias de pruebas selectivas de Fuerzas Armadas y Fuerzas y Cuerpos de Seguridad del Estado.

En este sentido, las federaciones deportivas que solicitan exámenes serológicos de VIH injustificadamente para negar la participación, no solo estarían atentando contra la dignidad de una persona por un acto discriminatorio, sino también estarían actuando en contra del ordenamiento jurídico que reconoce y garantiza la igualdad y libre participación deportiva a todas las personas sin distinción de su condición. Además, estarían violando tratados y convenios internacionales suscritos por España que tienen el objetivo de reducir la brecha social de discriminación en contra de las personas que conviven con VIH. 


\section{Investigación de campo}

La investigación de campo ejecutada consistió en contactar a la totalidad de federaciones deportivas dentro de la Comunitat Valenciana, con el objetivo de solicitar información referente a los requisitos que solicitan para que un deportista pueda acceder a la condición de federado. Contactamos con ellas mediante correo electrónico. El primer requerimiento de información fue enviado el 8 de febrero de 2019 y el segundo el 28 de febrero de 2019.

De las 60 federaciones dentro de la Comunitat Valenciana consultadas, 41 de ellas no respondieron a nuestra solicitud de información.

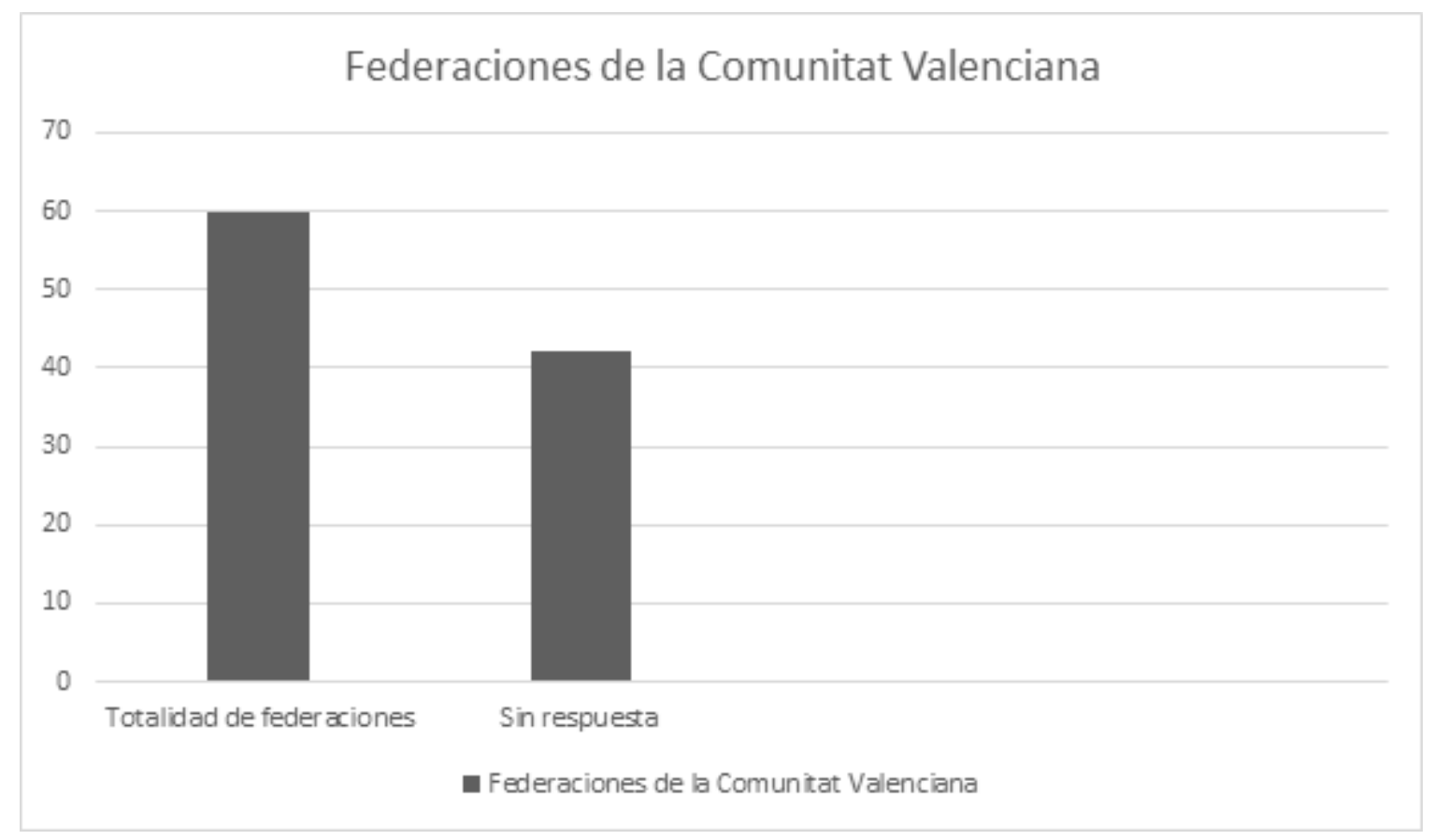

Recibimos respuesta de 19 federaciones de la Comunitat Valenciana, de las cuales 10 nos indicaron que solicitan un formulario únicamente con datos personales. 


\section{Federaciones de la Comunitat Valenciana}

70

60

50

40

30

20

10

0

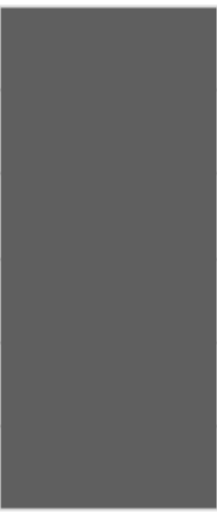

Totalidad de feder aciones

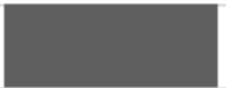

Formular io con datos personales

- Federaciones de la Comuntat Valenciana

En cuanto a la petición de reconocimientos o exámenes médicos, 3 federaciones lo solicitan, pero ninguna de ellas una prueba serológica, 5 no solicitan exámenes médicos y 1 federación solicita examen serológico (Federación de Boxeo de la Comunitat Valenciana).

\section{Federaciones Comunitat Valenciana}

70

60

50

40

30

20

10

0

Totalidad de feder aciones

Examenes médicos

No solicitan exámenes médicos

Examen serógico

- Federaciones Comunitat Valenciana 
Gráfico final de investigación de campo

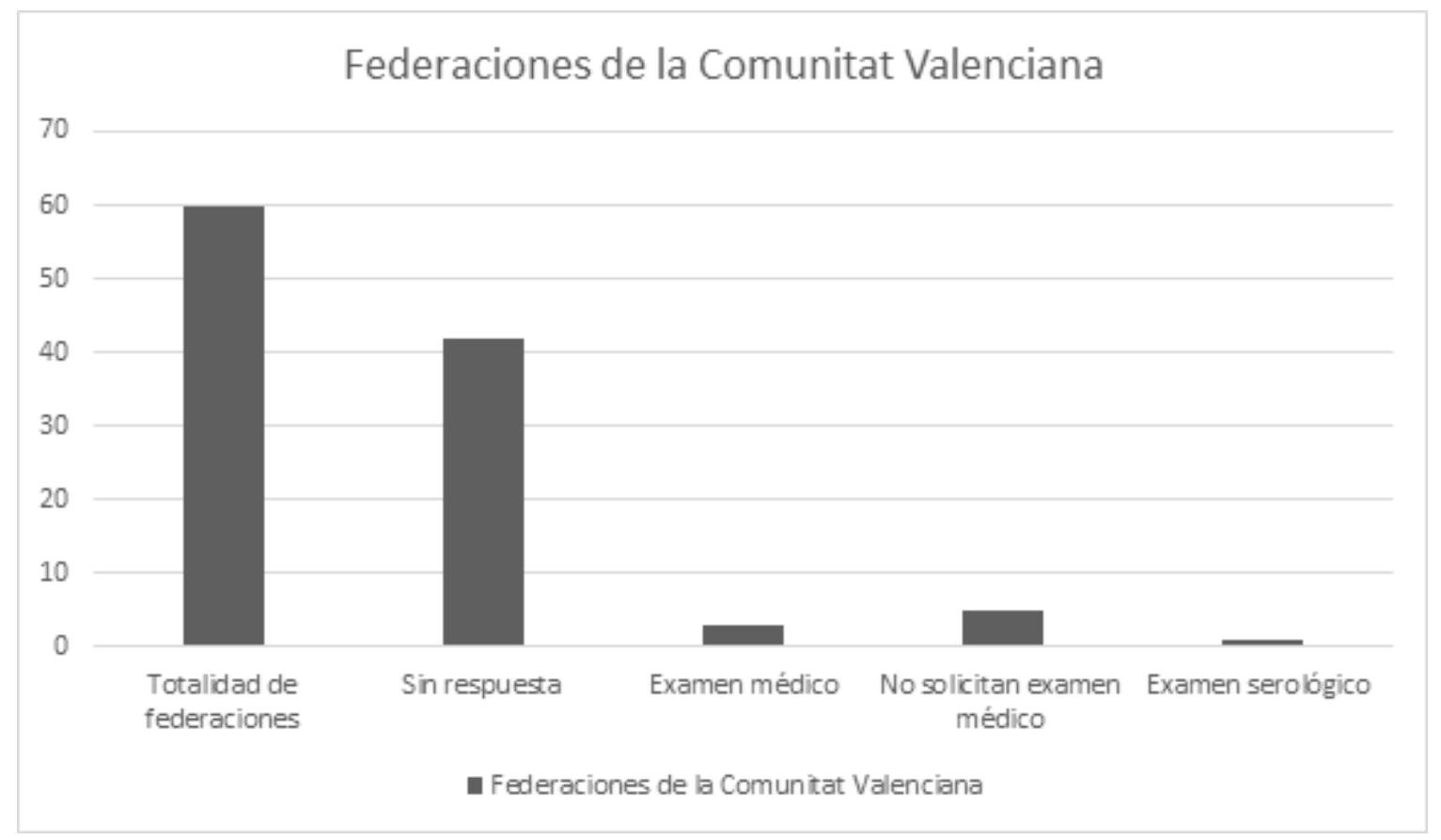




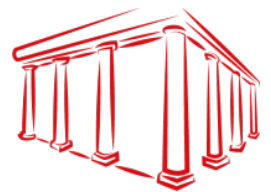

\section{Conclusiones}

Tras el análisis realizado y con el fin de sintetizar las conclusiones alcanzadas, cabe destacar las siguientes ideas principales. En primer lugar, la circunstancia analizada resultó ser una situación totalmente pertinente para el análisis jurídico por parte de un equipo como el de la Clínica Jurídica de la Universidad de Valencia, pues ha quedado comprobado que se está produciendo una situación clara de discriminación que afectaba potencialmente a la vida personal de una parte de la población.

Además, a lo largo del análisis ha quedado comprobado que, efectivamente, la petición de exámenes serológicos de VIH no está justificados y por tanto se confirman como ilegítimo, al afectar derechos humanos y principios constitucionales que protegen la intimidad, la igualdad de trato y no discriminación para cualquier persona sin importar su condición.

Estos derechos, desde su proclamación en la Declaración Universal de los Derechos Humanos y con el paso del tiempo, han servido de base para la elaboración de nuevos derechos contemplados en la legislación internacional y un claro ejemplo lo encontramos en la protección del derecho a la vida privada de las personas, proclamado tanto en el Pacto Internacional de Derechos Civiles y Políticos como en el Convenio Europeo de Derechos Humanos, estableciendo que ninguna persona puede ingerir o irrespetar en la vida privada de otra, ni de su familia o su honra, como se lo hace al pedir exámenes médicos para conocer la condición de forma injustificada.

Además, sostenemos la ilegitimidad de solicitar exámenes serológicos de VIH previos a federarse, por carecer esta práctica de un sustento legal que justifique su exigencia. Además, la repercusión que tendría presentar un examen médico de VIH positivo a una federación que lo exige nos conduciría a una exclusión que da como resultado una violación al derecho de trato igualitario y de discriminación directa.

Los actos de discriminación que sufren las personas que conviven con VIH se producen en una pluralidad de ámbitos y escenarios, incluyendo el deportivo, y por esta razón se han elaborado varios documentos como la Declaración Final de la Cumbre de París sobre el SIDA de 1994, la Resolución 1996/43, de 19 de abril, de la Comisión de Derechos Humanos de las Naciones Unidas para la protección de los derechos humanos de las personas 
que conviven con VIH o con SIDA, los Objetivos de Desarrollo del Milenio, entre otros, que obligan a los Estados miembros a promover acciones para proteger e integrar a las personas que conviven con VIH, de los cuales se ha obtenido buenos resultados, pero como observamos, no son suficientes.

Respecto de la legislación interna, la Constitución española alineada con los principios de derechos humanos, consagra el derecho a la libertad, a la no discriminación y a la igualdad formal y material, que encarga a los poderes públicos la capacidad de garantizar una real y efectiva igualdad a las personas. Así, al existir una brecha social importante entre las personas que conviven con VIH y las que no, el Estado debería legislar con el objetivo de reducirla, para así evitar la discriminación e impulsar su participación.

Es cierto que el Estado español se ha interesado por erradicar la violencia, el racismo, la xenofobia y la intolerancia en el deporte a través de la expedición de la Ley 19/2007, de 11 de julio y ha conformando comisiones, unidades de control y reglamentos para su desarrollo y aplicación, pero no hasta el momento para proteger a los deportistas que conviven con VIH contra actos que atenten contra su vida privada o discriminatorios, lo cual nos dejaría como resultado un visible incumplimiento del derecho de igualdad material establecida por el artículo 9.2CE.

Por otro lado, si bien la solicitud de un reconocimiento o examen médico se encuentra contemplado por la legislación vigente con el objetivo de proteger la salud del deportista y lucha contra el dopaje en la actividad deportiva, permitiendo a las federaciones deportivas solicitarlos, su finalidad debe ser siempre proteger al deportista para evitar posibles contraindicaciones en el ejercicio concreto de un determinado deporte, por lo que un examen serológico para comprobar una condición de VIH no se sujeta a esta a esta realidad.

En este sentido, la solicitud de exámenes serológicos de VIH a las personas que desean obtener una licencia deportiva por parte de una federación, no solo es ilegítima por atentar contra la voluntariedad de la persona o ser solicitada sin justificación legal alguna, sino por el gran contenido discriminatorio que conlleva ya que el VIH acarrea una serie de estigmas sociales que se ven reforzados con este tipo de situaciones discriminatorias no se pueden amparar en un Estado social y democrático de Derecho como el español. 


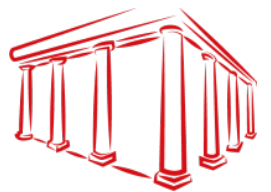

\section{Referencias Bibliográficas}

Coordinadora Estatal de VIH y Sida (CESIDA) y Grupo de Trabajo sobre Tratamientos del VIH (gTt-VIH). "VIH, discriminación y derechos, Guía para personas que viven con el VIH”, octubre 2015.

MARTIN, BOROWSKI (2000), "La restricción de los derechos fundamentales", Revista Española de Derecho Constitucional, 20, 59, 29-56.

HERNÁNDEZ, JUANSE, “VIH, deporte y derechos”. LMP43, Verano 2009.

PÉREZ LUÑO, ANTONIO-ENRIQUE (2018), La universalidad de los derechos humanos. Sevilla: Universidad de Sevilla.

PRIETO SANCHÍS LUIS, (1995), "Los derechos sociales y el principio de igualdad sustancial", Revista del centro de estudios constitucionales" 17

ONU, Informe de ONUSIDA, (2004).

RAMIRO AVILÉS MIGUEL. Á. y PAULINA, RAMÍREZ CARVAJAL, "VIH y Privacidad”, Proyecto de Clínica Legal de CESIDA, Madrid: Universidad de Alcalá.

\subsection{Referencias Legislativas}

- Declaración Universal de los Derechos Humanos, 1948.

- Declaración de la Cumbre de París sobre el SIDA 1 de diciembre de 1994

- Resolución de la Comisión de Derechos Humanos 1996/43, de 19 de abril, sobre la protección de los derechos humanos de las personas infectadas con VIH/SIDA

- Convenio Europeo de Derechos Humanos. 1977.

- Objetivos de Desarrollo del Milenio (ODM). 2000.

- Observación General Número 16. del Comité de Derechos Humanos. $32^{\circ}$ período de sesiones (1988). Derecho a la intimidad (artículo 17).

- Observación General Número 28 del Comité de Derechos Humanos. La igualdad de derechos entre hombres y mujeres (artículo 3)1, 2000. párrafo 20

- Constitución Española de 1978.

- España. Ley del Deporte 10/1990, de 15 de octubre 
- España. Ley Orgánica 3/2013, de 20 de junio, de protección de la salud del deportista y lucha contra el dopaje en la actividad deportiva.

- España. Ley 2/2011, de 22 de marzo, del deporte y la actividad física de la Comunitat Valenciana.

- España. Orden PCI/154/2019, de 19 de febrero, por la que se publica el Acuerdo del Consejo de Ministros de 30 de noviembre de 2018, por el que se aprueban instrucciones para actualizar las convocatorias de pruebas selectivas de personal funcionario, estatutario y laboral, civil y militar, en orden a eliminar ciertas causas médicas de exclusión en el acceso al empleo público. 